\title{
BREVES CONSIDERAÇÕES SOBRE O DIREITO DOS REFUGIADOS ECONÔMICOS E O INSTITUTO INTERNACIONAL DO ASILO
}

\section{BRIEF OBSERVATIONS ON ECONOMIC REFUGEES RIGHTS AND ASYLUM INTERNATIONAL INSTITUTE}

\author{
${ }^{1}$ Thiago Giovani Romero \\ ${ }^{2}$ Ana Cristina Alves de Paula
}

\section{RESUMO}

O artigo versa sobre a atual situação dos chamados refugiados econômicos e a incessante busca de garantias para a sua proteção. De início, mostrar-se-á a reconstituição histórica sobre a proteção internacional dos refugiados e breves notas sobre o pensamento de Hannah Arendt. Através da comparação de conceitos, visa esclarecer as diferenças entre os institutos do asilo e do refúgio. Apresentará o conceito clássico de refugiados e as novas categorias: refugiados ambientais e econômicos. Justifica-se o tema pela definição trazida pelo Estatuto do Refugiado de 1951, por não ser estendida aos refugiados econômicos. Optou-se pelo método dedutivo, através de revisão bibliográfica.

Palavras-chave: Refugiados econômicos, Asilo, Proteção internacional, Direitos humanos

\begin{abstract}
The article deals with the current situation of so-called economic refugees and the incessant search for guarantees for their protection. Initially, it will show to historical reconstruction of the international protection of refugees and brief notes on the thought of Hannah Arendt. By comparing concepts, aims to clarify the differences between asylum and refuge institutes. Present the classic concept of refugees and new categories: environmental and economic refugees. Justified the theme by setting brought by the Refugee Status, 1951, not be extended to economic refugees. We opted for the deductive method, through literature review.
\end{abstract}

Keywords: Economic refugees, Asylum, International protection, Human rights

\footnotetext{
${ }^{1}$ Mestrando em Direito pela Universidade Estadual Paulista Júlio de Mesquita Filho - UNESP, São Paulo Brasil. E-mail: thiago.romero@live.com

${ }^{2}$ Mestranda em Direito pela Universidade Estadual Paulista Júlio de Mesquita Filho - UNESP, São Paulo (Brasil). E-mail: a.cris.direito@gmail.com
} 


\section{INTRODUÇÃO}

No contexto da economia globalizada, da revolução dos transportes e das telecomunicações, ao mesmo tempo em que cresceu substancialmente o número de pessoas em mobilidade e se diversificaram os lugares de origem, trânsito e destino, tornaram-se frequentes as migrações forçadas (representadas principalmente pelos refugiados e deslocados internos) e o êxodo de migrantes que fogem de situações de miserabilidade e buscam ingressar nos países mais desenvolvidos.

O presente artigo tem por escopo uma breve análise sobre a Convenção Relativa ao Estatuto dos Refugiados de 1951 e o Protocolo de 1967, bem como questionar a sua adequação em face da nova realidade contemporânea no tocante à problemática dos refugiados econômicos. O tema é objeto de intensos debates nas Nações Unidas, pois, ao lado da exigência de maior cooperação e coordenação entre organizações humanitárias, destaca-se a existência de lacunas na legislação internacional e a necessidade de uma maior definição de regras para proteção e prestação de assistência a este grupo de migrantes particularmente vulneráveis. À luz de uma concepção globalizante será apreciado o art. 14 da Declaração Universal dos Direitos Humanos de 1948, a qual introduz a concepção contemporânea dos direitos humanos como universais e inerentes à condição de pessoa e não relativas às peculiaridades sociais e cultuais de determinada sociedade, incluindo em seu elenco o direito de asilo e o instituto do refúgio.

\section{BREVE RECONSTITUIÇÃO HISTÓRIA DA TRADIÇÃO QUE CULMINOU NA PROTEÇÃO INTERNACIONAL DOS REFUGIADOS}

No período anterior à Primeira Grande Guerra, não havia uma necessidade pulsante de uma mobilização internacional no sentido de assegurar a proteção a indivíduos perseguidos no interior de seus próprios Estados, bastando à época os institutos do asilo e da extradição (CUNHA, 2008, p. 178). Porém, com a Segunda Guerra Mundial, o problema dos refugiados tomou proporções jamais vistas, com o deslocamento de milhões de pessoas por diversas partes do mundo.

Luiz Paulo Teles F. Barreto leciona que, no ano de 1943, os aliados criaram a UNRRA (Administração de Socorro e Reabilitação das Nações Unidas.) e promoveram a Conferência de Bermudas, que ampliou a proteção internacional, definindo como refugiados: 
Todas as pessoas de qualquer procedência que, como resultado de acontecimentos na Europa, tiveram que abandonar seus países de residência por terem em perigo suas vidas ou liberdade, devido a sua raça, religião ou crenças políticas (BARRETO, p. 2).

No final de 1946, a Assembleia Geral criou a Organização Internacional para os Refugiados (OIR), primeiro organismo internacional investido no mandato temporário de registrar, proteger, instalar e repatriar refugiados. Cedo se tornou evidente que a responsabilidade pelos refugiados merecia um maior esforço da comunidade internacional, a ser desenvolvido sob os auspícios da própria Organização das Nações Unidas (NAÇÕES UNIDAS, 2004, p. 9).

Assim, muito antes de terminar o mandato da OIR, iniciaram-se as discussões sobre a criação de uma organização que lhe pudesse suceder. Na sua Resolução 319 (V) de 03 de dezembro de 1949, a Assembleia Geral decidiu criar o Alto Comissariado das Nações Unidas para os Refugiados - ACNUR - instituição apolítica, humanitária e social, com a função de proporcionar proteção internacional aos refugiados (BARBOSA; DA HORA, 2007, p. 18). O Alto Comissariado, cuja sede se localiza em Genebra, foi instituído em 01 de janeiro de 1951, como órgão subsidiário da Assembleia Geral, com um mandato inicial de três anos. Desde então, o mandato do ACNUR tem sido renovado por períodos sucessivos de cinco anos, encontrando-se representado, atualmente, em mais de cem países.

Três anos após a adoção da Declaração Universal de Direitos Humanos de 1948, foi aprovada a Convenção de Genebra relativa ao Estatuto dos Refugiados, de 1951, considerada a Magna Carta dos refugiados e requerentes de asilo e instrumento fundamental de proteção internacional dos refugiados, dispondo sobre seus direitos e deveres. Flávia Piovesan explica que a Convenção de 1951 estabeleceu uma limitação temporal e geográfica, uma vez que a condição de refugiado se restringia aos acontecimentos ocorridos antes de $1^{\circ}$ de janeiro de 1951 no continente europeu.

Isso significa que os refugiados somente eram assim reconhecidos se o fossem em decorrência de episódios ocorridos antes de $1^{\circ}$ de janeiro de 1951. Embora aplicável a milhares de pessoas - já que até a década de 50 a maioria dos refugiados era europeia - tal definição mostrou-se inoperante com o decorrer do tempo (PIOVESAN, 2010, p. 179).

Para que seus dispositivos continuassem a ter aplicação, foi aprovado o Protocolo sobre o Estatuto dos Refugiados, de 31 de janeiro 1967, que suprimiu as palavras "como resultado de acontecimentos ocorridos antes de $1^{\circ}$ de janeiro de 1951", as quais aparecem na Convenção, tornando, assim, aplicáveis seus dispositivos a casos futuros (PIOVESAN, 2010, p. 180). 
O conceito de refugiado, tal como é definido na Convenção de 1951 e no Protocolo de 1967, apresenta uma base jurídica apropriada para a proteção universal dos refugiados, o que não impede a ampliação da definição clássica com vistas a facilitar sua aplicação em situações de fluxos maciços de refugiados. Tanto é que, especialmente nos âmbitos regionais africano e americano, verifica-se o esforço de ampliar e estender o conceito de refugiado, merecendo destaque a Convenção da Organização de Unidade Africana de 1969 - a qual introduz uma nova concepção de refugiado, ao estender a proteção a todas as pessoas que são compelidas a cruzar as fronteiras nacionais em razão de agressão, ocupação ou dominação estrangeira ou perturbação da ordem pública, independentemente da existência do temor de perseguição -, e a Declaração de Cartagena sobre os Refugiados de 1984, que abrangeu em sua definição de refugiado as pessoas que fugiram de seus países porque sua vida, segurança ou liberdade foram ameaçadas pela violência generalizada, pela agressão estrangeira, pelos conflitos internos, pela violação maciça dos direitos humanos ou por outras circunstâncias que hajam perturbado gravemente a ordem pública. (PIOVESAN, 2010, p. 181)

\section{HANNAH ARENDT E A QUESTÃO DOS REFUGIADOS}

Inicialmente, Hannah Arendt traz uma terminologia humanista para ser usada no lugar de "refugiados", ou seja, trata-os chamando de "recém-chegados" ou "imigrantes". Assim, tínhamos um refugiado como aquela pessoa que se vê obrigada a buscar refúgio em razão de algum acto cometido ou posicionamento político. Em um conceito mais atual, os refugiados são pessoas que deixaram seu país de origem e chegaram a um novo, sem nenhuma infraestrutura, sendo auxiliados pelos Comitês de Refugiados (ARENDT, 2013, p.7).

Arendt, em um contexto pós- $2^{\text {a }}$ Guerra, aborda a questão dos apátridas, resultante dos processos de desnacionalização, retratando o sentimento de inferioridade que estas pessoas sofrem por não se sentirem inclusas à parte alguma. Isto porque, a nacionalidade é responsável pela formação de identidade da pessoa em razão do seu país.

Segundo Olivia Fürst Bastos (2001, p.304):

A realidade dessas populações, obrigadas a deixar seus países de origem e sem perspectiva de voltar ao lar, trouxe à tona o difícil problema dos apátridas: indivíduos que, ao deixarem seu Estado, perdiam sua nacionalidade e, em consequência, todos os demais direitos, passando a formar um grupo que não fazia parte de nenhum país. Arendt coloca em 
evidencia o sofrimento destes grupos, aos quais, subitamente, já não se aplicavam as regras do mundo que os rodeava.

Verificamos que no último século, em decorrência das Grandes Guerras, deparamonos com a figura dos refugiados, e principalmente, sobre as questões que envolvem os imigrantes ilegais. Esta temática é tratada pelo Direito Internacional, através da Convenção dos Refugiados de 1951, que traz a seguinte definição por Cosella (2001, pp. 19 e 20):

A expressão refugiados se aplica a qualquer pessoa que, em virtude de fundado medo de sofrer perseguição por motivos de raça, religião, nacionalidade, participação em determinado grupo social ou convicção política, se encontra fora do país da qual é nacional e está impossibilitada ou, em virtude, desse fundado medo, não deseja entregar à proteção deste país.

Logo, em virtude da desnacionalização, surge um alto contingente de pessoas sem Estado, buscando um novo país. Estes, por sua vez, encontram dificuldades em receber estas massas populacionais, tentando repatriá-los ou deportá-los aos países de origem, independentemente se estes querem ou não recebê-los. Notório que estamos diante de um fluxo sem controle de pessoas, que se soma com carência de tratamento pelos países receptores, resultando no esfacelamento do direito de asilo, considerado um marco das lutas pelos Direitos Humanos (BASTOS, 2001).

Assim, deparamo-nos com a chamada obrigação de solidariedade, que segundo Marcio Pereira Pinto Garcia (2001, p.148) é o “dever de assistir quem dele necessita, o dever de solidariedade de todos nós para com a dor do ser humano forçado a deixar sua terra natal, sua pátria".

Hannah Arendt traz um questionamento importante, quando aborda o direito a ter direitos ou o direito que cada indivíduo tem de pertencer à humanidade, que no âmbito da temática proposta dos refugiados, devemos observar nas suas próprias palavras que o garantidor é a população mundial (MICHELMAN, 1995 p. 14), segue:

Humanidade, que para o século XVIII... nada mais significava do que uma idéia reguladora, hoje se tornou um fato do qual não se pode escapar. Essa nova situação, na qual [a]" humanidade" assumiu de fato o papel anteriormente prescrito à natureza ou história, significaria neste contexto que o direito a ter direitos ou o direito que cada indivíduo tem de pertencer à humanidade, deve ser garantido pela própria humanidade.

Podemos utilizar uma indicação de Celso Lafer (1979, p.308), que trata da reconstrução dos direito humanos por intermédio da obra de Hannah Arendt, para evidenciar uma garantia aos refugiados, onde devemos "ver na cidadania o direito a ter direitos, uma vez 
que a igualdade não é um dado, mas uma consciência coletiva construída que requer por isso espaço público".

Diante das breves notas sobre o pensamento de Hannah Arendt, a questão dos refugiados está diretamente ligada à forma como deve ser valorizada as condições do homem, compreendendo a sua totalidade e utilizando o direito.

\section{O DIREITO DE ASILO}

$\mathrm{O}$ asilo, em que pese ter a mesma origem histórica do refúgio, desenvolveu-se de forma independente. O refúgio é um instituto jurídico internacional, como medida humanitária, enquanto que o asilo é instituto jurídico regional cuja concessão varia de Estado para Estado, classificando-se como medida essencialmente política. Desde sua origem até o século XVIII, ele foi aplicado como uma instituição fundamentalmente religiosa, ligada ao princípio da inviolabilidade dos lugares sagrados, e, apenas no século XIX veio a se laicizar, tornando-se objeto de normas jurídicas, que têm uma função precisa de tutela a perseguidos políticos (BOBBIO; MATTEUCCI; PASQUINO, 1998, p. 57).

Com o desenvolvimento das relações estatais, consolidou-se a necessidade de maior cooperação internacional no combate ao crime, assentando-se a aplicação do asilo a criminosos políticos e a extradição aos criminosos comuns.

$\mathrm{O}$ asilo se distingue em duas modalidades principais: asilo territorial e asilo extraterritorial. A doutrina, por vezes, também se refere a outras modalidades de asilo de menor importância - o naval (no interior de embarcações de guerra), o aeronáutico (em aeronaves militares) e o militar (em casernas ou acampamentos militares) (MAZZUOLI, 2012, p. 753). Fala-se ainda da modalidade "neutral", quando o asilo, em tempos de guerra, é concedido no território de um Estado neutro, mediante o respeito de determinadas condições, a tropas ou a navios de Estados beligerantes (BOBBIO; MATTEUCCI; PASQUINO, 1998, p. $57)$.

Em poucas palavras, pode-se conceituar asilo territorial como o acolhimento de um estrangeiro por parte de um Estado que não o seu, em virtude de perseguição praticada por seu próprio país. As causas motivadoras da perseguição, ensejadoras da concessão do asilo, em geral correspondem à dissidência política, à livre manifestação de pensamento ou, ainda, a prática de crimes relacionados com a segurança do Estado, desde que não configurem crimes no direito penal comum, reprováveis em qualquer parte do planeta (caso em que os Estados se 
ajudam mutuamente visando à sua repressão internacional). Ou seja, trata-se do recebimento de estrangeiro, em território nacional, sem os requisitos de ingresso, com o fito de preservar a sua liberdade ou a sua vida, colocadas em grave risco no seu país de origem, dado o desdobramento de convulsões sociais ou políticas. Daí o entendimento de que o asilo político é, antes de tudo, uma instituição humanitária, não sujeito, por isso mesmo, ao critério da reciprocidade.

Já o asilo extraterritorial ou diplomático é bastante utilizado nos países da América Latina, onde se tornou objeto de costumes particulares, provavelmente por causa da constante instabilidade política na região (PIOVESAN, 2010, p. 194). Esse asilo pode ser dado nas missões diplomáticas e, por extensão, nos imóveis cobertos pela inviolabilidade nos termos da Convenção de Viena de 1961, e, ainda, nos navios de guerra, acampamentos ou aeronaves militares. Conforme Valerio Mazzuoli, a autoridade asilante - via de regra, o embaixador examinará a ocorrência dos dois pressupostos referidos e, se os entender presentes, reclamará da autoridade local a expedição de um salvo conduto, com que o asilado possa deixar em condições de segurança o Estado territorial para encontrar abrigo definitivo no Estado que se dispõe a recebê-lo (2012, p. 756). Desta feita, ao contrário do asilo territorial, no asilo diplomático o Estado o concede fora do seu território, isto é, no território do próprio Estado em que o indivíduo é perseguido.

A concessão do asilo diplomático não implica necessariamente na outorga de asilo territorial. O asilo diplomático, em verdade, é uma modalidade de asilo territorial, dotada da característica da provisoriedade e precariedade (MAZZUOLI, 2012, p 756). Não estando o país disposto a conceder-lhe o asilo territorial, pode ser encaminhado a outro Estado que consinta em recebê-lo.Mas,se recebido no território nacional, presume-se que o governo já verificou as condições que justificam a concessão do asilo, permanecendo o estrangeiro sob a condição de asilado e a ele sendo fornecida a documentação necessária para a permanência no território nacional.

De acordo com Norberto Bobbio et al., o termo asilo indica, portanto, a proteção que um Estado concede a um indivíduo que busca refúgio em seu território ou num lugar fora de seu território, como direito fundamental da pessoa humana. O direito de asilo, por consequência, deve ser entendido como direito de um Estado de conceder tal proteção (BOBBIO; MATTEUCCI; PASQUINO, 1998, p. 58). Direito que começa, portanto, não no indivíduo, mas no Estado, em virtude do exercício da própria soberania e com a única reserva de eventuais limites derivados de convenções de que faça parte, e que termina com a naturalização do asilado no Estado asilante; com a sua saída voluntária; sua eventual expulsão 
(em casos de atentado contra a ordem pública ou os costumes locais); ou com o seu recebimento pelo governo de seu Estado de origem, quando lhe for concedida anistia ou quando lá se lhe reconhecer formalmente a sua inocência.

\section{O ARTIGO 14 DA DECLARAÇÃO UNIVERSAL DE DIREITOS HUMANOS DE 1948}

Para Flávia Piovesan, a Declaração Universal de 1948 é um marco do processo de construção do Direito Internacional dos Direitos Humanos, que conjugou o catálogo dos direitos civis e políticos aos direitos econômicos, sociais e culturais, dado que, com a internacionalização dos direitos humanos, definiram-se as novas diretrizes da ordem pública mundial, baseada, sobretudo, no respeito à dignidade humana (PIOVESAN, 2010, p. 196).

Há uma relação estreita entre a Convenção de 1951 e a Declaração Universal de 1948, sendo hoje impossível conceber o Direito Internacional dos Refugiados de maneira independente e desvinculada do Direito Internacional dos Direitos Humanos. É sob essa perspectiva que há de se enfocar o direito de asilo, na medida em que se exige uma visão necessariamente integral dos direitos da pessoa humana. Afirma o art. XIV da Declaração Universal que

1 - Todo homem, vítima de perseguição, tem o direito de procurar e de gozar asilo em outros países.

2 - Este direito não pode ser invocado em caso de perseguição legitimamente motivada por crimes de direito comum ou por atos contrários aos objetivos e princípios das Nações.

Os condenados por crimes de guerra, contra a humanidade e contra a paz encontramse absolutamente excluídos da possibilidade de receber asilo, assim como as pessoas condenadas por crimes não políticos graves também se encontram excluídas.

A afirmação do art. XIV lembra a Convenção sobre Asilo Territorial, segundo a qual, nos termos do seu art. $1^{\circ}$, todo Estado "tem direito, no exercício de sua soberania, de admitir dentro de seu território as pessoas que julgar conveniente, sem que, pelo exercício desse direito, nenhum outro Estado possa fazer qualquer reclamação".

A Declaração Americana dos Direitos e Deveres do Homem, de 1948, também deixou expresso, no seu art. 27, que "toda pessoa tem o direito de procurar e receber asilo em território estrangeiro, em caso de perseguição que não seja motivada por delitos de direito comum, e de acordo com a legislação de cada país e com as convenções internacionais". Por 
fim, a Assembleia-Geral da ONU, em 14 de dezembro de 1967, adotou a Resolução 2.314, denominada Declaração sobre Asilo Territorial, na qual se reconheceu que "a concessão de asilo por um Estado a pessoas que tenham direito de invocar o art. 14 da Declaração Universal [...] é um ato pacífico e humanitário e que, como tal, não pode ser considerado inamistoso por nenhum outro Estado".

As declarações e convenções acima citadas têm valor programático. Elas não obrigam, diretamente, os Estados-membros das Nações Unidas, mas exercem uma notável influência, pelo menos psicológica, sobre o comportamento dos seus órgãos de governo e dos seus juízes (BOBBIO; MATTEUCCI; PASQUINO, 1998, p. 58). O instituto do asilo tem apenas uma motivação atualmente, que é justamente a que o diferencia do instituto do refúgio: a imputação ao asilado da prática de um crime político ou de um crime comum conexo a um delito político.

O direito de asilo pode ser limitado, no plano convencional, por tratados relativos à extradição (acordos internacionais, geralmente bilaterais, mas às vezes também multilaterais, pelos quais os Estados se comprometem reciprocamente a entregar uns aos outros os indivíduos procurados, em outro Estado, por delitos previstos nos mesmos acordos).

Em conformidade com o próprio instituo do asilo, e muitas vezes também com os princípios expressos nos ordenamentos internos, mesmo a nível constitucional, é característica nestes tratados a tendência a excluir os delitos políticos do número dos reatos para os quais está prevista a extradição, frente ao fenômeno do terrorismo em âmbito mundial, que motiva, desde o século passado, algumas iniciativas de organizações internacionais, governamentais ou não, tendentes a impedir a impunibilidade do terrorista expatriado (BOBBIO; MATTEUCCI; PASQUINO, 1998, p. 58).

A motivação que enseja as situações de asilo político e refúgio é distinta, ou seja, enquanto aquele se aplica em situações de perseguição de modo nitidamente mais individual, este tem por causa determinantes situações que atingiram sempre uma coletividade (REZEK, 2000, p. 198). Mas a principal diferença entre os institutos jurídicos do asilo e do refúgio reside no fato de que o primeiro constitui exercício de um ato soberano do Estado, sendo decisão política cujo cumprimento não se sujeita a nenhum organismo internacional. Já o segundo, sendo uma instituição convencional de caráter universal, aplica-se de maneira apolítica, visando a proteção de pessoas com fundado temor de perseguição.

Acrescente-se que a concessão de asilo possui caráter constitutivo, enquanto que o reconhecimento da condição de refugiado é ato declaratório. Cada Estado deve considerar que a decisão sobre a concessão de asilo pode determinar a vida ou a morte de uma pessoa, 
devendo adotar um processo rápido, flexível e liberal perante a dificuldade que se apresenta para documentação da perseguição.

\section{A RESPONSABILIDADE DO ESTADO NA CONCESSÃO DE ASILO}

Os processos para determinar se um indivíduo se enquadra nos critérios de qualificação como asilado ou se é necessária outra forma de proteção internacional devem ser céleres, equitativos e eficazes. Além disso, de acordo com Flávia Piovesan (2010, p. 191), a concessão do asilo a uma pessoa que, carecendo da proteção que deveria ter em seu país de origem, vê-se obrigada a buscar tal proteção fora dele, deve ser reconhecida como ato de natureza pacífica, apolítica e essencialmente humanitária. Por isso, é de importância fundamental o princípio inscrito na Declaração da ONU sobre Asilo Territorial de 1967 de que a concessão de asilo não pode jamais ser interpretada como um ato inamistoso, de inimizade ou hostilidade com relação ao país de origem do solicitante. Ela depende da instauração de um processo de asilo, contanto que o caso se inclua na alçada de proteção da Convenção de Genebra de 1951 e se processe no próprio país de origem do indivíduo perseguido ou na embaixada do país de destino, caracterizando-se como ato discricionário do Estado que concede o beneficio no uso do exercício de sua soberania.

Coaduna-se com o entendimento da referida autora, pois, embora a Declaração Universal, em seu art. 14, consagre o direito fundamental de solicitar asilo e dele gozar, discutese qual a responsabilidade do Estado no processo de concessão de asilo. Na prática de muitos Estados signatários da Convenção de 1951 e do Protocolo de 1967, o refugiado não apenas tem efetivamente usufruído o asilo no sentido de residência, como também tem sido protegido da devolução forçosa ao país no qual há o risco de perseguição ou outra grave ameaça (princípio do non-refoulement) (PIOVESAN, 2010, p. 192).

Para que os procedimentos referentes à decisão sobre a concessão de asilo sejam justos e satisfatórios, devem existir as seguintes condições: 1) o organismo encarregado de adotar as decisões deve ser independente, especializado e alheio a ingerências políticas; 2) todas as solicitações de asilo devem ser examinadas pessoalmente por um entrevistador qualificado e especializado em Direito Internacional dos Direitos Humanos, bem como Direito dos Refugiados; 3 ) as refugiados devem ter a opção de ser entrevistadas por mulheres; 4) em todas as etapas do processo devem estar presentes intérpretes competentes, qualificados e imparciais; 5) todas as solicitações de asilo devem ser estudadas de forma individual e exaustiva; 6) os solicitantes devem dispor de assistência; 7) os solicitantes devem ter um tempo para preparar sua petição e buscar uma assistência jurídica; 8) os 
solicitantes de asilo que estiverem sem a documentação necessária devem gozar do benefício da dúvida, em vista de suas especiais circunstâncias; 9) os solicitantes de asilo devem ter o direito de permanecer no país até que se faça pública a solução final de seu pedido (PIOVESAN, 2010, p. 191).

Contudo, a ilustre estudiosa afirma ainda existir uma forte resistência dos Estados em aceitar um instrumento internacional que estabeleça deveres acerca da concessão de asilo, sob o argumento de que decisão nesse sentido situar-se-ia no domínio da soberania e discricionariedade estatal.

Há a necessidade de reduzir o alcance da discricionariedade do Estado, a fim de que direitos universalmente assegurados sejam efetivamente implementados. Vale dizer, ao direito de solicitar asilo e dele gozar, enunciado na Declaração Universal, há de corresponder o devedor do Estado de conceder asilo. Adotando-se a perspectiva da proteção dos direitos humanos, faz-se fundamental consolidar a teoria da responsabilidade jurídica do Estado no tocante à matéria. Ao conceder asilo a uma pessoa, assegurando-lhe direitos básicos, a atuação do Estado está absolutamente afinada com a concepção contemporânea de direitos humanos, no que tange à universalidade e à indivisibilidade (PIOVESAN, 2010, p. 198).

A fim de que direitos universalmente assegurados sejam efetivamente implementados, premente é a necessidade de reduzir o domínio da discricionariedade do Estado, visto que, atualmente, a ele cabe decidir quem deve ser admitido e quem pode nele permanecer. Adotando-se a teoria da responsabilidade jurídica do Estado no tocante à matéria, consoante Flávia Piovesan, assegurar-se-á que a atuação esteja absolutamente afinada com a concepção contemporânea de diretos humanos, permitindo aos asilados e refugiados a reconstrução de suas vidas na sociedade que os acolherá.

\section{A CONVENÇÃO SOBRE O ESTATUTO DOS REFUGIADOS E A CONCEPÇÃO CONTEMPORÂNEA DOS DIREITOS HUMANOS}

Inicialmente, os principais instrumentos para a garantia e preservação dos direitos humanos, em especial ao tratamento dos refugiados, encontram-se na Convenção das Nações Unidas de 1951 e no Protocolo Adicional de 1967.

A Convenção de 1951 é conhecida como a Carta Magna de proteção aos refugiados, por estabelecer a definição destas pessoas, como seus direitos e deveres. A principal crítica que encontramos é que a determinada tratativa definiu o termo "refugiado" de maneira limitada. 
Significa que os refugiados somente serão assim reconhecidos, se o forem em decorrência de episódios ocorridos antes dessa precisa data: $1^{\circ}$ de janeiro de 1951. Desse modo, tal definição seria aplicada a muitos milhares de pessoas mas, com o decorrer do tempo, a definição da Convenção se tornaria inoperante (TRINDADE; PEYTRIGNET; SANTIAGO, 1996, pp. 267 e 268).

Pela existência desta limitação de conceito foi estabelecido,em 31 de janeiro de 1967, o Protocolo Adicional sobre o Estatuto dos Refugiados, com o objetivo de ampliar o alcance do conceito de refugiado existente no artigo $1^{\circ}$ do instrumento exordial.

Art. $1^{\circ}$ Será reconhecido como refugiado todo indivíduo que: I - devido a fundados temores de perseguição por motivos de raça, religião, nacionalidade, grupo social ou opiniões políticas encontre-se fora de seu país de nacionalidade e não possa ou não queira acolher-se à proteção de tal país.

Nota-se na doutrina clássica a existência de três vertentes que assistem a proteção internacional dos direitos humanos: Direitos Humanos, Direito Humanitário e Direito dos Refugiados. Mas, atualmente, esta visão segmentada encontra-se em desuso, pois se busca ampliar as normas de garantia visando assegurar os direitos inerentes ao homem em todos os campos (SANTIAGO, 1996, p. 30).

Inicia-se um movimento de internacionalização dos direitos humanos, amparada por Richard B. Bilder (1992, pp. 3-5):

É baseado na concepção de que toda nação tem a obrigação de respeitar os direitos humanos de seus cidadãos e de que todas as nações e a comunidade internacional têm o direito e a responsabilidade de protestar, se um Estado não cumprir suas obrigações. O Direito Internacional dos Direitos Humanos consiste em um sistema de normas, procedimentos e instituições internacionais desenvolvidos para implementar esta concepção e promover o respeito dos direitos humanos em todos os países, no âmbito mundial.

Ao tratarmos sobre o direito internacional dos refugiados, constatamos que o seu objetivo é garantir e estabelecer direitos humanos mínimos aos indivíduos que saem dos seus países de origem, deixando tudo para trás, buscando um novo meio social (SAADEH; EGUCHI, 1998).

Segundo Jayme Ruiz de Santiago (1996, p. 129), a problemática acerca dos refugiados surge em razão das violações dos direitos humanos básicos, que deveriam ser respeitados em todo o processo de solicitação de asilo ou refúgio.

O mesmo autor (1996, p. 230) traz o seguinte entendimento:

O direito internacional dos refugiados está intimamente vinculado ao Direito Internacional dos Direitos Humanos e ao Direito Internacional Humanitário, sobretudo com a normativa internacional sobre Direito Humanos, na medida 
em que esta se aplica a toda pessoa humana, independentemente de sua condição ou origem.

O direito internacional é o instrumento capaz de garantir a proteção dos direitos humanos, nos âmbitos global e interno de cada Estado, a todo ser humano. Em especial, notase que a garantia dos direitos dos refugiados não se aplica a todos os homens, pois é necessário o exame de algumas circunstâncias especiais (SAADEH; EGUCHI, 1998).

Portanto, em uma visão contemporânea a respeito dos direitos humanos, conclui-se que o direito humanitário e o direito dos refugiados são peças fundamentais, existentes dentro do sistema de proteção internacional, buscando estabelecer um núcleo garantidor: a preservação da vida humana, por meio de assegurar direitos básicos de subsistência.

\section{A PROTEÇÃO INTERNACIONAL DOS DIREITO HUMANOS}

Evolutivamente, ao tratar da proteção dos direito humanos, lembramo-nos do ensinamento de Hannah Arendt (1979), que consiste em dizer que os direitos humanos não são um dado, mas uma invenção humana em um processo constante de construção e reconstrução.

Ao encontro do entendimento de Arendt, afirma Ignacy Sachs (1998, p. 156):

Não se insistirá nunca o bastante sobre o fato de que a ascensão dos direitos é fruto de lutas, que os direitos são conquistados, às vezes, com barricadas, em um processo histórico cheio de vicissitudes, por meio do qual as necessidades e as aspirações se articulam em reivindicações e em estandartes de luta antes de serem reconhecidos como direitos.

Não menos importante, Norberto Bobbio (1988, p.30) retrata a condição dos direitos humanos, em seu livro "Era dos Direitos", como:

Os direitos humanos nascem como direitos naturais universais, desenvolvem-se como direitos positivos particulares (quando cada Constituição incorpora Declarações de Direito), para finalmente encontrarem sua plena realização como direitos positivos universais.

Não há dúvidas sobre a ascensão da internacionalização dos direitos humanos, principalmente a partir do final da $2^{\mathrm{a}}$ Guerra Mundial, que trouxe a figura do sistema internacional de proteção.

O movimento de internacionalização dos direitos humanos constitui um movimento extremamente recente na história, surgindo, a partir do pós- guerra, como resposta às atrocidades e aos horrores cometidos durante o nazismo. Se a $2^{\text {a }}$. Guerra significou a ruptura com os direitos humanos, o 
Pós-Guerra deveria significar a sua reconstrução. É neste cenário que se desenha o esforço de reconstrução dos direitos humanos, como paradigma e referencial ético a orientar a ordem internacional contemporânea(PIOVESAN, 2001, pp. 1 e 2).

Em 1945, a Carta da Organização das Nações Unidas (ONU) entrou em vigor, com a ideia de um governo mundial, tendo como objetivo a paz entre os Estados e mobilizar a comunidade internacional para combater o desrespeito e promover os direitos humanos. (HUSEK, 2010, p. 214).

A Assembleia Geral da ONU, em 1948, elaborou a Declaração Universal dos Direitos do Homem, de modo que introduziu uma concepção contemporânea sobre os direitos humanos, revestida com características de universalidade e indivisibilidade.

Universalidade porque a condição de pessoa é o requisito único e exclusivo para a titularidade de direitos, sendo a dignidade humana o fundamento dos direitos humanos. Indivisibilidade porque, ineditamente, o catálogo dos direitos civis e políticos é conjugado ao catálogo dos direitos econômicos, sociais e culturais (PIOVESAN, 2001, p. 2).

Notamos que foi com o advento da Declaração de 1948, que houve o início do direito internacional sobre os direitos humanos, ou seja, um processo de universalização de direitos para a formação de um sistema internacional de proteção, suportado pela ONU.

Neste contexto, a problemática dos refugiados deve ser abordada no âmbito dos direitos humanos, por haver uma inter-relação; afinal, o refúgio está amparado com as normas de preservação da vida humana, expressas na Declaração de 1948(ACNUR, 1990, Conclusão $\left.n^{\circ} .56\right)$.

Nota-se que o sistema de proteção para os direitos humanos é efetivado por tratados internacionais, fundamentados em um consenso ético e assecuratório que compartilham os Estados. Portanto, a participação crescente dos Estados-partes nestes tratados configura um grau de alinhamento internacional sobre a preservação da vida humana, através dos direitos humanos (PIOVESAN, 2001, p. 3).

Não menos importante, Antonio Augusto Cançado Trindade (1997), evidencia a problemática do monismo e dualismo, em razão da participação dos Estados em senso comum de proteção internacional dos direitos humanos, que devem efetivar prioritariamente os direitos inerentes da pessoa humana, independente da primazia do direito internacional ou do seu direito interno. Vejamos:

Desvencilhamo-nos das amarras da velha e ociosa polêmica entre monistas e dualistas; neste campo de proteção, não se trata de primazia do direito internacional ou do direito interno, aqui em constante interação: a primazia 
é, no presente domínio, da norma que melhor proteja, em cada caso, os direitos consagrados da pessoa humana, seja ela uma norma de direito internacional ou de direito interno.

Arrematando o que foi exposto por Trindade, Flávia Piovesan (2001, p. 4) menciona que os "direitos internacionais constantes dos tratados de direitos humanos apenas vêm a aprimorar e fortalecer, nunca a restringir ou debilitar, o grau de proteção dos direitos consagrados no plano normativo constitucional".

Evidentemente, podemos concluir que os mecanismos internacionais de proteção dos direitos humanos exigem dos Estados-partes uma redefinição interna do conceito de cidadania. Afinal, o Estado que ratifica um tratado internacional de direitos humanos deve manter um diálogo paralelo com a sua legislação interna, para que não haja contradições que possam prejudicar os direitos e garantias fundamentais do seu povo, em consequência ao bom funcionamento do sistema de proteção internacional.

É fundamental a interação entre o catálogo de direitos nacionalmente previstos e o catálogo de direitos internacionais, com vistas a assegurar a mais efetiva proteção aos direitos humanos. Impõe-se ainda ao Estado o dever de harmonizar a sua ordem jurídica interna à luz dos parâmetros mínimos de proteção dos direitos humanos - parâmetros estes livremente acolhidos pelos Estados (PIOVESAN, 2001, p. 4).

Conforme menciona Cançado Trindade (1997, p.112): “O ser humano passa a ocupar, em nossos dias, a posição central que lhe corresponde, como sujeito de direito tanto interno quanto internacional".

\section{OS NOVOS REFUGIADOS}

É inegável que o direito de asilo tende a sofrer, sobretudo nos últimos anos, profundas transformações, reflexo da mudança nas exigências e características de uma sociedade profundamente modificada em sua estrutura. Visto que a Convenção sobre o Estatuto dos Refugiados foi elaborada num contexto em que se atentava apenas para os chamados direitos humanos de primeira geração, isto é, aqueles ligados às liberdades civis e políticas, o direito internacional passou a distinguir claramente o conceito de refugiados das demais categorias de migrantes.

Contudo, a rigidez do diploma legal objeto do presente estudo gera uma nova problemática, a ser enfrentada pelo Direito Internacional dos Refugiados, visto que milhões de pessoas restam totalmente à margem do sistema nacional e internacional de proteção à 
pessoa humana, por não se encaixarem na definição clássica do que venha a ser um refugiado. Neste diapasão vislumbram-se os refugiados econômicos.

Na perspectiva dos direitos humanos, esta situação suscita uma grande preocupação, pois nem sempre é possível distinguir, com segurança, um refugiado de um imigrante econômico. Mas, à parte destas considerações, fato é que, independentemente da classificação, a pessoa deve se beneficiar dos direitos humanos básicos. Consorte Ana Paula da Cunha, a Convenção de 1951 é fruto de um tempo e de um espaço específicos e deve ser constantemente renovada, visando acompanhar a dinamicidade da ordem social contemporânea, caracterizada pela supremacia dos direitos humanos e pela relativização das soberanias estatais, com vistas a se erigir a proteção à pessoa humana como norte teleológico dos sistemas jurídicos nacionais e internacional (CUNHA, 2008, p. 10).

\title{
9. OS REFUGIADOS ECONÔMICOS
}

O fluxo migratório das pessoas entre as fronteiras é comum em diversos momentos da história e acontecem pelos mais variados motivos como a necessidade econômica, a fuga de conflitos armados em determinada região, até mesmo por sofrerem perseguições ideológicas (SOUSA; BENTO, 2013, p.25).

Portanto, diante do crescimento dos fluxos migratórios e visando uma garantia de direitos básicos, o Estatuto dos Refugiados de 1951, traz em seu artigo $1^{\circ}$ a definição sobre quem será considerado refugiado. Vejamos:

\begin{abstract}
Art. $1^{\circ}$ Será reconhecido como refugiado todo indivíduo que: I - devido a fundados temores de perseguição por motivos de raça, religião, nacionalidade, grupo social ou opiniões políticas encontre-se fora de seu país de nacionalidade e não possa ou não queira acolher-se à proteção de tal país; II - não tendo nacionalidade e estando fora do país onde antes teve sua residência habitual, não possa ou não queira regressar a ele, em função das circunstâncias descritas no inciso anterior; III - devido a grave e generalizada violação de direitos humanos, é obrigado a deixar seu país de nacionalidade para buscar refúgio em outro país.
\end{abstract}

De acordo com Sousa e Bento (2013, p.27), esta definição apresentada pelo artigo $1^{\circ}$ do Estatuto dos Refugiados não é capaz de enquadrar as demais categorias de pessoas que abandonam seus países de origem, porque os temores de perseguição por motivos de raça, religião, nacionalidade, grupo social ou opiniões políticas formam uma delimitação, não abrangendo outros motivos que se relacionam diretamente com a questão dos direitos humanos. 
Nesta linha de pensamento, encontramos as margens da garantia dos refugiados as chamadas novas categorias, formadas pelos refugiados ambientais e os refugiados econômicos.

Em síntese, por não ser o núcleo do presente trabalho, mas para que haja compreensão sobre a categoria dos refugiados ambientais, podemos utilizar o conceito desenvolvido por Essam El-Hinnawi (1985):

Pessoas que fogem ou deixam sua terra natal em função de ameaças de vida e segurança provocadas pelo ambiente, dentre essas ameaças quaisquer mudanças físicas, químicas e biológicas nos ecossistemas ou diretamente nos recursos naturais que o transformam tornando o ambiente impróprio para manter ou reproduzir a vida humana.

Já o refugiado econômico, segundo a definição de Paulo Borba Cosella (2001, p.24) é aquele que "se vê diante da impossibilidade total de satisfazer suas necessidades vitais no país do qual é nacional”.

Nesta linha, importante esclarecer a figura do migrante econômico, que nas palavras do mesmo autor (2001, p. 24) é aquele que "poderia, ao menos em tese, subsistir em seu país natal, mas, insatisfeito com as condições locais, se desloca para outra região, em busca de melhores perspectivas".

Portanto, o migrante econômico é revestido de voluntariedade na sua migração; antagonicamente, é o refugiado econômico que é forçado a sair do seu país de origem, por não haver possibilidade de satisfação das necessidades básicas (CUNHA, 2008, p.192).

Os refugiados econômicos carecem de proteção internacional, pois seu fluxo migratório é forçado, como foi citado acima. Merece destaque Jean Ziegler, relator da Comissão de Direitos Humanos das Nações Unidas para o Direito à Alimentação, que defende esta categoria de refugiados, abaixo (CUNHA, 2008, p.193):

Necessidade de reconhecer como autênticos refugiados aqueles indivíduos que deixam seus países de origem ou de nacionalidade por conta de graves crises alimentares que põem em risco a vida de milhares de cidadãos. Contudo, consoante este pensador, a proteção político-jurídica deveria ser temporária, isto é, enquanto durasse a crise alimentar por que passa o país de origem.

Infelizmente, os refugiados econômicos não são reconhecidos e estão sem as garantias de proteção que traz a Convenção de 1951. Por isso, é necessária uma ampliação do conceito elencado no artigo $1^{\circ}$ do Estatuto. Estes não podem ficar a margem do ordenamento jurídico de proteção a dignidade da pessoa humana. Sabe-se que o Estado de origem é 
responsável garantidor, devendo estabelecer e alinhar políticas públicas para que os seus nacionais possam ter condições dignas de sobrevivência (SOUSA; BENTO, 2013, p.44).

Concluímos que a Convenção dos Refugiados não ampara em seu texto legal as novas categorias de pessoas, mas que indiscutivelmente, necessitam da proteção internacional dos seus direitos básicos, já que seus países de origem não oferecem condições dignas de subsistir. Logo, estas pessoas esperam através do auxílio de outros países a efetivação dos direitos humanos, as quais são protagonistas.

\section{CONSIDERAÇÕES FINAIS}

A consolidação dos princípios de Direitos Humanos constituiu um grande passo para reduzir a intolerância que provoca instabilidade em diversas regiões do mundo. Tanto o instituto do asilo quanto o do refúgio relacionam-se à proteção da pessoa humana vitimada por perseguições, protegendo indivíduos independentemente de sua nacionalidade. Afinal, a intolerância não constrói a dignidade de um povo, mas, ao contrário, obriga milhões de pessoas a se deslocarem de seus países de origem em busca de proteção à vida e à liberdade, que jamais deveriam estar ameaçadas.

É fundamental entender que cada solicitante de refúgio ou asilo é consequência de um padrão de violação de direitos humanos. Daí a necessidade de fortalecer a dimensão preventiva relacionada ao asilo e remover ou reduzir as condições que levam as pessoas a abandonar seus lares, mediante a proteção de vítimas potenciais (TRINDADE, p. 1).

Advoga-se, neste sentido, a necessidade de ampliação da Convenção de 1951 diante dos chamados refugiados econômicos, que ficam à margem de qualquer proteção nacional e internacional por não gozarem da proteção do instituto universal do refúgio segundo a definição formal trazida pelo referido diploma legal.

$\mathrm{Na}$ visão contemporânea acerca dos refugiados econômicos, mediante os instrumentos de garantia dos direitos humanos, devem estabelecer a preservação da vida humana, por meio de assegurar direitos básicos de subsistência.

Concluímos que a Convenção dos Refugiados, mesmo não amparando expressamente em seu texto legal as novas categorias de refugiados (ambientais e econômicos), devem ampliar a sua visão e garantir a estas pessoas a mínima inclusão em um novo contexto social. 


\section{REFERÊNCIAS}

ACNUR, Conclusiones sobre laproteccion internacional de los refugiados. Genebra, 1990.

ARENDT, Hannah. As origens do totalitarismo. Trad. Roberto Raposo, Rio de Janeiro, 1979.

ARENDT, Hannah. Nós, os refugiados. Covilhã: LusoSofia:press, 2013, p. 7. Disponível em: <http://www.lusosofia.net/textos/20131214-hannah_arendt_nos_os_refugiados.pdf>. Acesso em: 21 jun 2015.

BARRETO, Luiz Paulo Teles F. Das diferenças entre os institutos jurídicos do asilo e do refúgio. Disponível em: <www.migrante.org.br/IMDH/.../das_diferentes_entre_os_institutos.doc>. Acesso em: 23 jun. 2015.

BARROS, Olivia Fürst.Hannah Arendt e o tema dos refugiados, IN:. O Direito internacional dos Refugiados: Uma perspectiva Brasileira, Coordenadores: Nadia de Araujo e Guilherme Assis de Almeida. Rio de Janeiro: EditoraRenovar, 2001.

BILDER, Richard. An overview of international human rights law, IN: Hurst hannum, guide to international rights practice.2. ed., Philadelphia: UniversityofPennsylvania Press, 1992.

COSELLA, Paulo Borba. Refugiados: conceito e extensão, IN:. O Direito internacional dos Refugiados: Uma perspectiva Brasileira, Coordenadores: Nadia de Araujo e Guilherme Assis de Almeida. Rio de Janeiro: Editora Renovar, 2001.

BOBBIO, Norberto; MATTEUCCI, Nicola; PASQUINO, Gianfranco. Dicionário de política. 11. ed. Brasília: Editora UnB, 1998.

CUNHA, Ana Paula da.O direito internacional dos refugiados em xeque: refugiados ambientais e econômicos. Revista Brasileira de Direito Internacional, Curitiba, v.8, n.8, jul/dez. 2008.

EL-HINNAWI,Essam. Environmental Refugees. United Nations Environmental Program, Nairobi, 1985.

FIORATI, Jete Jane. Os direitos do homem e a condição humana no pensamento de Hannah Arendt. Revista de Informação Legislativa. Brasília, a. 36, n. 142, abr./jun. 1999.

GARCIA, Marcio Pereira Pinto. Refugiado: o dever de solidariedade, IN:. O Direito internacional dos Refugiados: Uma perspectiva Brasileira, Coordenadores: Nadia de Araujo e Guilherme Assis de Almeida. Rio de Janeiro: Editora Renovar, 2001.

HUSEK, Carlos Roberto. Curso de direito internacional. 10ª Ed. São Paulo: Ltr. 2010. LAFER,

Celso. Hannah Arendt, pensamento, persuasão e poder. São Paulo. Paz e Terra. 1979.

MAZZUOLI, Valerio de Oliveira. Curso de direito internacional público. 6. ed. rev., atual. eampl. São Paulo: Editora Revista dos Tribunais, 2012. 
MICHELMAN, Frank I. Draft: A right to have Rights: Jurisprudential and Logical Analysis. s, vol. 3, issue 2, 1995.

$O$ direito a requerer asilo, a proteção em relação à perseguição e o princípio da não repulsão (non-refoulement). Disponível em: <http://www.fd.uc.pt/igc/manual/pdfs/P.pdf>. Acesso em: 23 jun. 2015.

PIOVESAN, Flávia Cristina. Sistema internacional de direitos humanos. I Colóquio Internacional de Direitos Humanos. São Paulo, Brasil, 2001. Disponível em: $<$ http://www.dhnet.org.br/direitos/sip/textos/a_pdf/piovesan_sip.pdf>. Acesso em: 21 jun. 2015.

Temas de direitos humanos. 4. ed. São Paulo: Saraiva, 2010.

REZEK, José Francisco. Direito Internacional Público. 8. ed., São Paulo: Saraiva, 2000.

SAADEH, Cyro; EGUCHI, Mônica Mayumi. Convenção relativa ao estatuto dos refugiados: protocolo sobre o estatuto dos refugiados. São Paulo, 1998. Disponível em: <http://www.pge.sp.gov.br/centrodeestudos/bibliotecavirtual/direitos/tratado12.htm>. Acesso em 23 jun. 2015.

SACHS, Ignacy. Desenvolvimento, direitos humanos e cidadania, In: Direitos Humanos no Século XXI, 1998.

SOUSA, Mônica Teresa Costa; BENTO, Leonardo Valles. Refugiados econômicos e a questão do direito ao desenvolvimento. Cosmopolitan Law Journal, v. 1, n. 1, dez. 2013.

TRINDADE, Antônio Augusto Cançado. Tratado de Direito Internacional dos Direitos Humanos. Vol. 1. Porto Alegre: Sérgio Antônio Fabris Editor, 1997.

- Direito internacional dos direitos humanos, direito internacional humanitário e direito internacional dos refugiados: aproximações ou convergências. Disponível em: <http://www.dhnet.org.br/direitos/sip/dih/didh.html>. Acesso em: 23 jun. 2015.

TRINDADE, Antônio Augusto Cançado; PEYTRIGNET, Gerárd; SANTIAGO, Jaime Ruiz. As três vertentes da proteção internacional dos Direitos Humanos da Pessoa Humana. San José da Costa Rica: IIDH, Comitê Internacional da Cruz Vermelha, Alto Comissariado das Nações Unidas para os Refugiados, 1996.

ZIEGLES, Jean. Réfugies de La faim:unarticleterriblementaccusateur de Jean Ziegler. Disponível em: <http://amapduperelachaise.free.fr/spip.php?article110>. Acesso em: 21 jun. 2015. 